\title{
Comparative effectiveness of torasemide versus furosemide in symptomatic therapy in heart failure patients: Preliminary results from the randomized TORNADO trial
}

\author{
Paweł Balsam ${ }^{1}$, Krzysztof Ozierański ${ }^{1}$, Michał Marchel ${ }^{1}$, Monika Gawałko , \\ Łukasz Niedziela ${ }^{1}$, Agata Tymińska ${ }^{1}$, Bartosz Sieradzki ${ }^{1}$, Maciej Sieradzki ${ }^{1}$, \\ Anna Fojt ${ }^{1}$, Elwira Bakuła ${ }^{2}$, Renata Główczyńska ${ }^{1}$, Michał Peller ${ }^{1}$, Maciej Markulis ${ }^{1}$, \\ Janusz Bednarski ${ }^{2}$, Robert Kowalik ${ }^{1}$, Andrzej Cacko ${ }^{1}$, Grzegorz Niewiński ${ }^{3}$, \\ Krzysztof J. Filipiak ${ }^{1}$, Grzegorz Opolski ${ }^{1}$, Marcin Grabowski ${ }^{1}$ \\ ${ }^{1} 1^{\text {st }}$ Chair and Department of Cardiology, Medical University of Warsaw, Poland \\ ${ }^{2}$ Cardiology Unit, John Paul II Western Hospital, Grodzisk Mazowiecki, Poland \\ ${ }^{3}$ Department of Anesthesiology and Intensive Care, Medical University of Warsaw, Poland
}

\begin{abstract}
Background: Recent reports suggest that torasemide might be more beneficial than furosemide in patients with symptomatic heart failure (HF). The aim was to compare the effects of torasemide and furosemide on clinical outcomes in HF patients.

Methods: This study pilot consisted of data from the ongoing multicenter, randomized, unblinded endpoint phase IV TORNADO (NCT01942109) study. HF patients in New York Heart Association (NYHA) II-IV class with a stable dose of furosemide were randomized to treatment with equipotential dose of torasemide (4:1) or continuation of unchanged dose of furosemide. On enrollment and control visit (3 months after enrollment) clinical examination, 6-minute walk test (6MWT) and assessment of fluid retention by ZOE Fluid Status Monitor were performed. The primary endpoint was a composite of improvement of NYHA class, improvement of at least $50 \mathrm{~m}$ during $6 M W T$ and decrease in fluid retention of at least $0.5 \Omega$ after 3-months follow-up.

Results: The study group included 40 patients (median age 66 years; $77.5 \%$ male). During follow-up 7 patients were hospitalized for HF worsening (3 in torasemide and 4 in furosemide-treated patients). The primary endpoint reached $15(94 \%)$ and 14 (58\%) patients on torasemide and furosemide, respectively $(p=0.03)$.

Conclusions: In HF patients treated with torasemide fluid overload and symptoms improved more than in the furosemide group. This positive effect occurred already within 3-month observation. (Cardiol J 2019; 26, 6: 661-668)
\end{abstract}

Key words: heart failure, hospitalization, loop diuretics, prognosis, symptoms

\section{Introduction}

Heart failure (HF) is one of the leading cardiovascular problems in Europe, with a prevalence of $1-2 \%$ in the adult population in developed countr- ies [1]. Despite an intensive delivery of healthcare and education to affected patients, its incidence continues to increase, resulting in $50 \%$ or greater mortality in a 5-year observation [1]. Loop diuretics are cornerstone in the treatment of signs of

Address for correspondence: Michał Marchel, MD, PhD, $1^{\text {st }}$ Department of Cardiology, Medical University of Warsaw, ul. Banacha 1a, 02-097 Warszawa, Poland, tel: +48 2259929 58, e-mail: michal.marchel@wum.edu.pl 
fluid overload and congestion in patients with HF. Despite rapid relief of symptoms in patients with acute decompensated HF, long-term use of these agents has been consistently associated with adverse events, including electrolyte disturbance, activation of the renin-angiotensin-aldosterone and the sympathetic nervous systems (RAAS and SNS), which could accelerate HF progression $[2,3]$.

Torasemide and furosemide are representatives of loop diuretics with an identical diuretic mechanism, but different pharmacokinetic properties and additional effects. Compared to furosemide, torasemide has greater bioavailability, a higher degree of protein binding, and a longer half-life. These properties make that torasemide works faster, longer and less frequently causes rapid micturition than furosemide. Torasemide after oral administration is well absorbed from the gastrointestinal tract, even in overhydration caused by heart, kidney and liver diseases. Moreover, torasemide potency is 4 times greater than furosemide. Torasemide also has anti-aldosterone activity and inhibits myocardial fibrosis and remodeling [4-8]. According to previous studies, torasemide decreases rates of $\mathrm{HF}$ hospitalizations and hospital stay, improves exercise tolerance, quality of life, left ventricular function, cardiac sympathetic nerve activity, myocardial fibrosis, pulmonary congestion, peripheral edema, and blood pressure compared with furosemide [9-12]. These favorable effects of torasemide suggest that this agent would be more beneficial than furosemide in patients with $\mathrm{HF}$.

The main purpose of the present study was comparison of the furosemide with torasemide's effects on HF symptoms, including New York Heart Association (NYHA) class, fluid retention and exercise tolerance in patients with HF.

\section{Methods}

\section{Study design}

This pilot study consisted of data from the ongoing multicenter, randomized, open, phase IV TORNADO (TORasemide oN hemodynAmic and Neurohormonal Stress, and carDiac remOdeling in Heart Failure) study, registered in ClinicalTrials. gov: NCT01942109. The study was approved by a local ethical review board and an informed consent was obtained from each patient. The detailed methods and description of the study design have been described previously [13]. Briefly, the study included patients who were hospitalized in years 2015-2018 in two cardiology centers in Poland, including academic center and a district hospital.
All patients were diagnosed with HF in NYHA II-IV class, irrespective of left ventricular ejection fraction (LVEF) and treated with optimal HF therapy. The diagnosis of HF, according to current guidelines [1], was based on clinical (typical HF signs and symptoms), echocardiographic and biochemical (increased concentrations of $\mathrm{N}$-terminal pro-B-type natriuretic peptide [NT-proBNP] or BNP parameters). All demographic, clinical, etiology of HF, laboratory data, as well as information on medication, were collected.

Heart failure patients on a stable dose of furosemide were randomized to the treatment with torasemide or unchanged treatment with furosemide (randomization 1:1). After randomization, furosemide has been continued in its current fixed-dose or was replaced by equipotential dose of torasemide (4:1, according to the previous studies and manufacturer's data [6]). Figure 1 shows the flow chart of the study design.

\section{Study endpoints}

During the baseline hospitalization and on control visit (3 months after enrollment) echocardiographic examination and 6 -minute walk test (6MWT) were performed. To assess the level of fluid retention, measurement of thoracic base impedance was made using ZOE Fluid Status Monitor. The device works in line with principle: the less resistance - impedance measured in ohms - the more fluid is in the chest.

In the current analysis the primary endpoint was a composite of improvement of NYHA functional class, improvement of at least $50 \mathrm{~m}$ during $6 \mathrm{MWT}$, and decrease of at least $0.5 \Omega$ in fluid retention after 3 months from recruitment. Different composite endpoint compared to the initially registered endpoints (i.e. events associated with $\mathrm{HF}$ - deaths, hospitalization) was purposely chosen because of low patient number and one-time functional assessment at 3-month follow up.

\section{Statistical analysis}

Continuous and ordinal variables are expressed as a median (interquartile range). Categorical data were presented as a number of patients and percentages. Group comparisons were performed using the Fisher exact test for qualitative variables and $t$ test for quantitative, normally distributed variables, and the Mann-Whitney U test for quantitative, non-normally distributed variables (normality of distribution was checked with the Shapiro-Wilk test). For all analyses, a p value of less than 0.05 was considered statistically significant. 


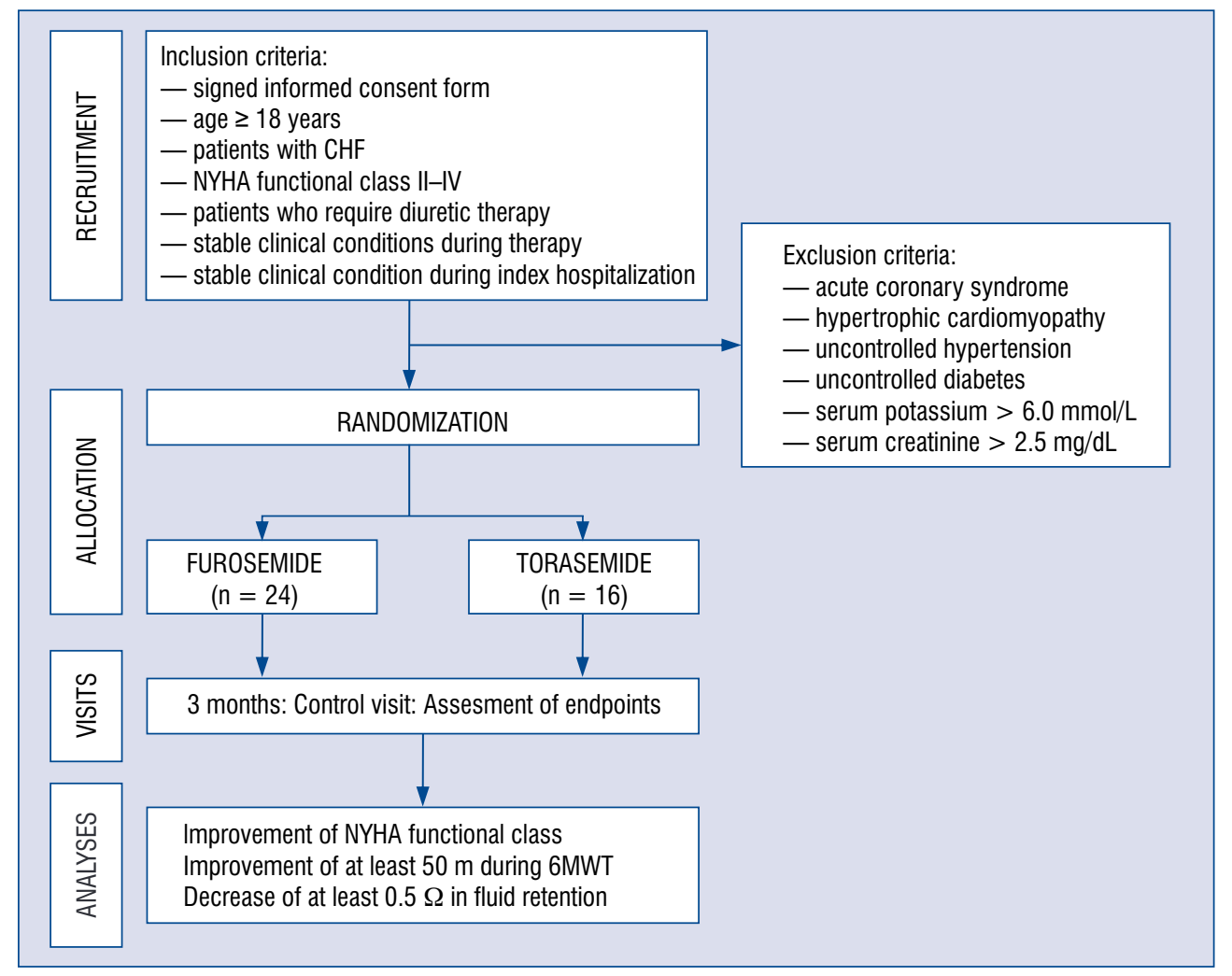

Figure 1. Flow chart of patient enrollment in the study; CHF — congestive heart failure; NYHA — New York Heart Association; 6MWT - six-minute walking test.

\section{Results}

\section{Baseline characteristics}

The current analysis of the TORNADO study included 40 patients. During hospitalization, $60 \%$ of them $(\mathrm{n}=24)$ were randomized to further treatment with furosemide and $40 \%(\mathrm{n}=16)$ to treatment with torasemide. Median age of the study group was 66 years and $77.5 \%$ were male. Mean diuretic dose (converted in a ratio of $4: 1$ on furosemide dose) was $100 \mathrm{mg}$ and $70 \mathrm{mg}$ in the furosemide and torasemide groups, respectively $(\mathrm{p}=0.16)$. Most common etiology of HF was ischemic heart disease $(50 \%)$. Patients in the torasemide and furosemide groups were similar in terms of age, gender, chronic diseases, NYHA class, LVEF, heart rate, systolic blood pressure, laboratory findings (serum concentrations of hemoglobin, creatinine, sodium, potassium, NT-proBNP), HF recommended pharmacotherapy (angiotensin converting enzyme inhibitor, angiotensin receptor blocker, beta-blocker, mineralocorticoid receptor blocker) and implantable devices (pacemaker, cardiac resynchronization therapy, cardioverter defibrillator). Baseline characteristics of both study groups are presented in Table 1.

\section{Follow-up admission}

Patients completed 3-months follow-up. During the follow-up 7 patients were hospitalized for $\mathrm{HF}$ worsening (3 vs. 4 in torasemide and furosemide groups, respectively). The primary endpoint reached $15(94 \%)$ patients of the torasemide group and $14(58 \%)$ patients of the furosemide group $(\mathrm{p}=0.03)$. The changes in NYHA functional class, 6MWT and ZOE Fluid Status Monitor test from baseline to the end of follow-up are presented in the Table 2 and Figures 2-4. During follow-up period, an equal percentage of patients treated with furosemide and torasemide reached primary endpoint in the NYHA class improvement form. Torasemide-treated patients were more often, but not statistically significant, observed to reach primary endpoint as improvement of at least $50 \mathrm{~m}$ during 6MWT $(\mathrm{n}=0.09)$ or decrease of at least $0.5 \Omega$ in fluid retention during 3 months as compared to patients on furosemide $(n=0.51)$. These results reflect a significant decrease in fluid retention and improvement in 6MWT in the whole torasemide group as compared to whole furosemide group in which increase in fluid retention and deterioration in 6MWT was observed. 
Table 1. Comparison of 40 patients with heart failure treated with furosemide or torasemide.

\begin{tabular}{|c|c|c|c|c|}
\hline Parameter & $\begin{array}{l}\text { All patients } \\
(n=40)\end{array}$ & $\begin{array}{l}\text { Furosemide } \\
\quad(n=24)\end{array}$ & $\begin{array}{c}\text { Torasemide } \\
(n=16)\end{array}$ & $\mathbf{P}$ \\
\hline \multicolumn{5}{|l|}{ Demographics } \\
\hline Age [years] & $66[51-81]$ & $65[58-80]$ & 74 [49-85] & 0.29 \\
\hline Gender [male] & $31(77.5)$ & $20(83.3)$ & $11(68.8)$ & 0.28 \\
\hline Body mass index $\left[\mathrm{kg} / \mathrm{m}^{2}\right]$ & $30[23-39]$ & $30[24-39]$ & $30[20-38]$ & 0.51 \\
\hline \multicolumn{5}{|l|}{ Heart failure } \\
\hline Symptoms of HF at admission & $12(30.0)$ & $6(25.0)$ & $6(37.5)$ & 0.40 \\
\hline Previous HF hospitalization & $25(62.5)$ & $16(67.7)$ & $9(56.3)$ & 0.51 \\
\hline \multicolumn{5}{|l|}{ Heart failure etiology: } \\
\hline Ischemic & $20(50.0)$ & $12(50.0)$ & $8(50.0)$ & 1.00 \\
\hline Hypertensive & $5(12.5)$ & $2(8.3)$ & $3(18.8)$ & 0.33 \\
\hline Dilated cardiomyopathy & $7(17.5)$ & $5(20.8)$ & $2(12.5)$ & 0.50 \\
\hline Valve disease & $2(5.0)$ & $2(8.3)$ & $0(0.0)$ & 0.24 \\
\hline NYHA [class] & $2[2-3]$ & $2[2-3]$ & $2[2-3]$ & 0.94 \\
\hline Ejection fraction [\%] & $37[27-52]$ & 35 [29-47] & 38 [24-54] & 0.93 \\
\hline \multicolumn{5}{|l|}{ Medical history } \\
\hline Smoking & $20(50.0)$ & $13(54.2)$ & $7(43.8)$ & 0.52 \\
\hline Ischemic heart disease & $19(47.5)$ & $11(45.8)$ & $8(50.0)$ & 0.80 \\
\hline Previous $\mathrm{CABG} / \mathrm{PCl}$ & $17(42.5)$ & $12(50.0)$ & $5(31.3)$ & 0.24 \\
\hline Hypertension & $23(57.5)$ & $14(58.3)$ & $9(50.0)$ & 0.896 \\
\hline Diabetes & $18(45.0)$ & $12(50.0)$ & $6(37.5)$ & 0.44 \\
\hline Dyslipidemia & $18(45.0)$ & $12(50.0)$ & $6(37.5)$ & 0.44 \\
\hline Atrial fibrillation & $17(42.5)$ & $9(37.5)$ & $8(50.0)$ & 0.58 \\
\hline Cardiac electronic implantable device & $17(42.5)$ & $9(37.5)$ & $8(50.0)$ & 0.58 \\
\hline Stroke/TIA & $2(5.0)$ & $2(8.3)$ & $0(0.0)$ & 0.27 \\
\hline Peripheral vascular disease & $5(12.5)$ & $3(12.5)$ & $2(12.5)$ & 1.00 \\
\hline Chronic kidney disease & $14(35.0)$ & $9(37.5)$ & $5(31.3)$ & 0.08 \\
\hline \multicolumn{5}{|l|}{ Clinical status } \\
\hline Heart rate $[\mathrm{bpm}]$ & $75[60-100]$ & 75 (18.5) & $80[60-100]$ & 0.95 \\
\hline Systolic BP [mmHg] & $135[110-160]$ & $135[116-160]$ & $133[100-150]$ & 0.29 \\
\hline Diastolic BP [mmHg] & 78 [64-101] & 80 [70-101] & $70[60-80]$ & 0.07 \\
\hline \multicolumn{5}{|l|}{ Laboratory findings } \\
\hline NT-proBNP [pg/mL] & $\begin{array}{c}1681 \\
{[483-5902]}\end{array}$ & $\begin{array}{c}2106 \\
{[656-7032]}\end{array}$ & $\begin{array}{c}1273 \\
{[374-5435]}\end{array}$ & 0.30 \\
\hline Sodium concentration [mmol/L] & 141 [137-146] & $141[137-146]$ & $141[138-144]$ & 0.56 \\
\hline Potassium concentration $[\mathrm{mmol} / \mathrm{L}]$ & $4.4[3.9-4.9]$ & $4.5[3.9-4.9]$ & $4.4[3.9-4.9]$ & 0.86 \\
\hline Creatinine concentration [mg/dL] & $1.3[0.9-1.8]$ & $1.3[1.0-1.9]$ & $1.2[0.7-1.6]$ & 0.10 \\
\hline \multicolumn{5}{|l|}{ Pharmacotherapy } \\
\hline Beta-blocker & $\begin{array}{c}34(89 \%) \\
N=38\end{array}$ & $\begin{array}{c}22(96 \%) \\
N=23\end{array}$ & $\begin{array}{c}14(93 \%) \\
N=15\end{array}$ & 0.76 \\
\hline ACEI & $\begin{array}{l}26(68) \\
N=38\end{array}$ & $\begin{array}{l}17(74) \\
N=23\end{array}$ & $\begin{array}{c}9(60) \\
N=15\end{array}$ & 0.37 \\
\hline Angiotensin receptor blocker & $\begin{array}{c}7(18) \\
N=38\end{array}$ & $\begin{array}{c}2(8.7) \\
N=23\end{array}$ & $\begin{array}{c}5(33) \\
N=15\end{array}$ & 0.06 \\
\hline Aldosterone antagonist & $\begin{array}{l}23(61) \\
N=38\end{array}$ & $\begin{array}{l}15(65) \\
N=23\end{array}$ & $\begin{array}{c}9(60) \\
N=15\end{array}$ & 0.75 \\
\hline
\end{tabular}

Values are showed as median (interquartile range) or number (percentage); ACEI — angiotensin-converting enzyme inhibitor; BP — blood pressure; CABG — coronary artery bypass grafting; $\mathrm{HF}$ - heart failure; $\mathrm{PCI}$ — percutaneous coronary intervention; TIA — transient ischemic attack 
Table 2. Changes in the components of the primary from baseline to the end of 3-month follow-up.

\begin{tabular}{|c|c|c|c|c|c|c|}
\hline \multirow[t]{2}{*}{ Variable } & \multicolumn{3}{|c|}{ Furosemide } & \multicolumn{3}{|c|}{ Torasemide } \\
\hline & $\begin{array}{c}\text { On } \\
\text { admission }\end{array}$ & $\begin{array}{l}\text { 3-month } \\
\text { follow up }\end{array}$ & $\mathbf{P}$ & $\underset{\text { On }}{\text { admission }}$ & $\begin{array}{l}\text { 3-month } \\
\text { follow up }\end{array}$ & $\mathbf{P}$ \\
\hline ZOE $^{\circledR}$ Fluid Status Monitor [Ohm] & $17(15-24)$ & $18(15-23)$ & 0.68 & $18(15-24)$ & $17(15-19)$ & 0.05 \\
\hline NYHA class & $3(2-3)$ & $2(1-3)$ & 0.37 & $3(2-4)$ & $2(2-3)$ & 0.18 \\
\hline 6MWT [m] & $309(172-450)$ & $320(120-454)$ & 0.10 & $243(120-432)$ & $340(100-500)$ & 0.29 \\
\hline
\end{tabular}

Values are showed as median (interquartile range); NYHA — New York Heart Association; 6MWT — six-minute walk test

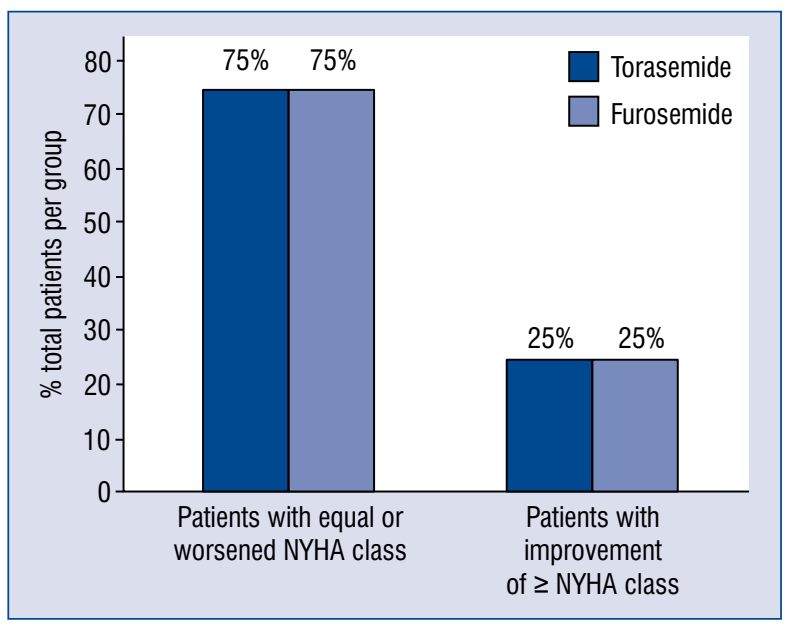

Figure 2. Changes in New York Heart Association (NYHA) functional class from baseline to the end of follow-up. The proportion of patients with/without NYHA class improvement ( $\geq 1$ NYHA class) from baseline to the end of 3-month follow-up in torasemide-treated patients $(p=0.77$ compared to furosemide-treated patients).

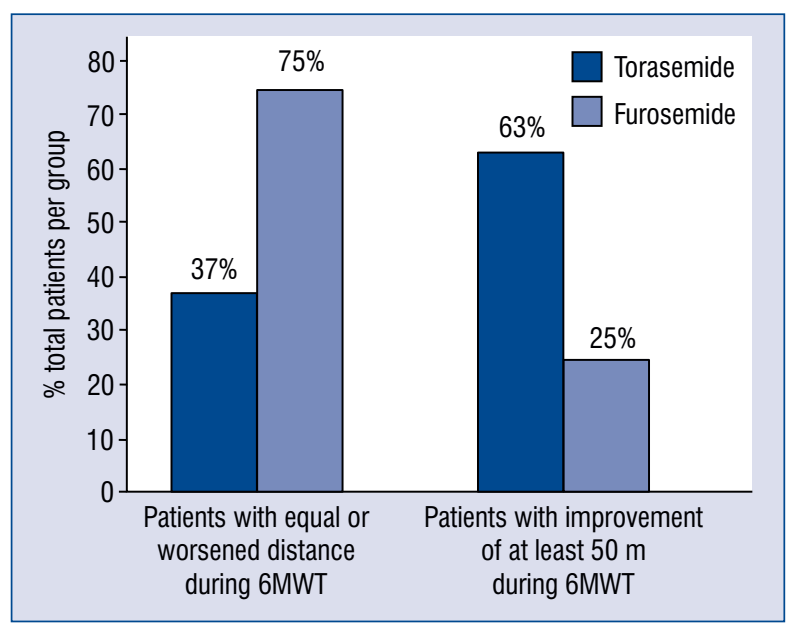

Figure 3. Changes in six-minute walk test (6MWT) from baseline to the end of follow-up. The proportion of patients with/without improvement in walking distance $(\geq 50 \mathrm{~m}$ ) during 6MWT from baseline to the end of 3-month follow-up in torasemide-treated patients ( $p=0.09$ compared to furosemide-treated patients).

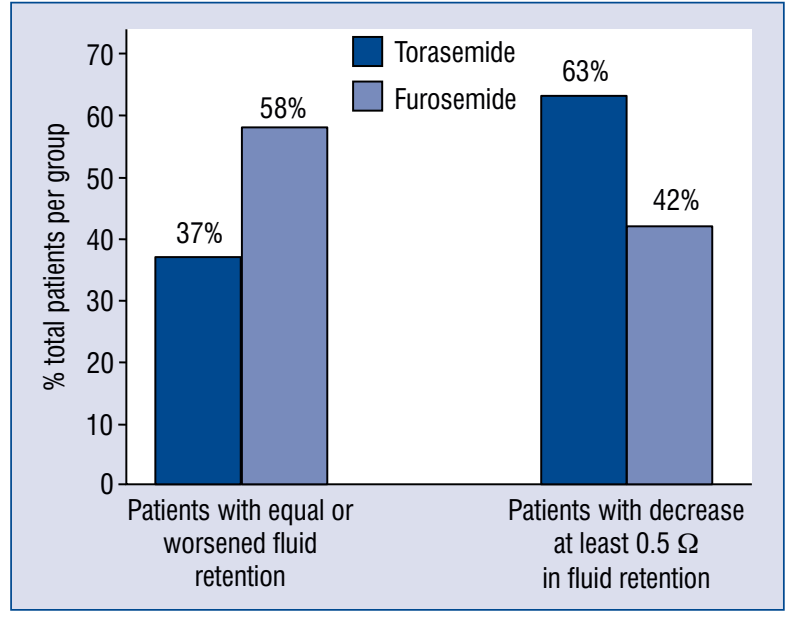

Figure 4. Changes in fluid retention from baseline to the end of follow-up. The proportion of patients with/without decrease $(\geq 0.5 \Omega)$ in fluid retention from baseline to the end of 3-month follow-up in torasemide-treated patients $(p=0.51$ compared to furosemide-treated patients).

\section{Discussion}

The results of this study showed that patients randomized to torasemide had a higher likelihood of reaching the primary composite endpoint of improvement of NYHA functional class, decreased fluid retention, elongated walking distance compared to patients randomized to furosemide. This may indicate that diuretic effect of torsemide compared to furosemide can cause the higher loss of body water leading to greater weight loss that can facilitate walking. Significant, but not statistically, improvement in walking distance and decreased fluid retention among torasemide-treated patients may be also explained by phenomenon of "regression to the mean" - which describes the tendency of extreme measurement on a first occasion to become less extreme when checked again. In this study, it was easier for a patient on torasemide to have a larger improvement in 6MWT and decrease 
in fluid retention if the initial walking distance was too low and fluid retention was too high.

Recently published data from the QUALIFY (QUAlity of adherence to guideline recommendations for Life-saving treatment in HF) survey, reported $70 \%$ adherence to the guideline-recommended drugs what reflects fairly satisfactory $\mathrm{HF}$ therapy [14]. The current HF guidelines recommended the use of loop diuretics as a class I indication to improve symptoms in HF patients with both reduced and preserved LVEF [1]. There is no clear answer which of the loop diuretics should be preferred. The favourable use of furosemide in $\mathrm{HF}$ might be explained by its early market introduction in 1960 s, whereas torasemide was approved by Food and Drug Administration in 1990s and became generic at the beginning of the twenty-first century. However, some studies suggest that torasemide outperform furosemide's clinical and economic properties by reducing hospital admissions and in-hospital stay [15-17].

Furosemide, the most commonly used loop diuretic in clinical practice, is known to activate the RAAS and the SNS, which could accelerate HF progression. In contrast to furosemide, torasemide was shown to have favorable effect on RAAS inhibition, through blockade of the aldosterone receptor $[4,5]$. Our analysis revealed that torasemide-treated patients tended to gain more benefits in symptomatic $\mathrm{HF}$ therapy than furosemide what emphasized the importance of obtaining prospective data comparing these two loop diuretics.

There are no previous studies showing direct comparison of torasemide and furosemide on fluid retention. Our study showed more pronounced decrease in fluid retention with torasemide than furosemide treatment. This probably translated into improved NYHA class and elongated walking distance in the torasemide group. Recent analysis from the Heart Failure Registries of the European Society of Cardiology revealed that use of torasemide was associated with significantly lower NYHA class comparing to furosemide treatment $(\mathrm{p}=$ $=0.04$ ). During follow-up torasemide use was associated with a lower risk $(12.9 \%$ vs. $20.0 \%$; $p=0.03)$ of worsening $\geq 1$ NYHA functional class $(12.9 \%$ vs. $20.0 \% ; p=0.03$ ) [18]. TORIC (TORasemide In Congestive HF) study that revealed significantly higher efficiency of torasemide than furosemide and other diuretics in functional improving of at least 1 grade in NYHA class $(45.8 \%$ vs. $37.2 \%$; $\mathrm{p}=0.00017$ ) [19]. It is in line with the metanalysis of Kido et al. [20] that showed that torasemide is associated with statistically significant improve- ment in NYHA functional class for patients with $\mathrm{HF}$ compared with furosemide $(\mathrm{p}=0.0004)$. However, torasemide did not provide significant benefits in reducing mortality or rehospitalization rates for $\mathrm{HF}(\mathrm{p}=0.15)$ or cardiovascular disease $(\mathrm{p}=0.22)$ compared with furosemide. Moreover, there was no significant difference in mortality between torsemide and furosemide $(\mathrm{p}=0.99)$.

According to large international ASCEND$\mathrm{HF}$ trial, clinicians tend to use torasemide in the setting of patients with features of more severe disease including refractory volume overload [21]. The preferential use of torsemide in these circumstances may be related to torasemide's smaller inter- and intraindividual variation in bioavailability, longer action increased bioavailability, longer half-life and maintained absorption in the setting of intestinal edema [6, 21, 22]. Moreover, diuretic therapy with torasemide instead of furosemide optimizes the quality of daily life of patients with $\mathrm{HF}$ by reducing number of mictions at 3,6 and $12 \mathrm{~h}$ after diuretic intake, and urgency to urinate $[6,13,22]$. Other studies have also demonstrated improvement in sympathetic nerve activity as well as decreased left ventricle volumes and levels of BNP with torsemide compared to furosemide therapy [23, 24]. Additional benefits with torsemide over furosemide include less urinary potassium loss resulted in reduced arrhythmia burden [25]. In DiNicolantonio et al. [7] meta-analysis of randomized controlled trials in 471 patients with systolic HF, compared with furosemide, torasemide caused a $14 \%$ reduction in all-cause mortality. It is in line with the TOrasemide In Congestive Heart Failure (TORIC) study results that reported significantly lower mortality in the torasemide $(n=17,2.2 \%)$ than in furosemide/other diuretics groups $(\mathrm{n}=27$, 4.5\%; $\mathrm{p}<0.05$ ) [19]. Analysis of the Polish parts of Heart Failure Registries of the European Society of Cardiology, Pilot and Long-Term, revealed that use of torasemide was associated with a significant $24 \%$ risk reduction of the composite endpoint of allcause death and hospitalization for worsening $\mathrm{HF}$ ( $26.4 \%$ vs. $34.7 \%$; $p=0.04)$. These benefits may be due to the additional advantages of torasemide such as anti-aldosterone effect [18].

Patients discharged after hospitalization for $\mathrm{HF}$ remain at high risk of death and hospital readmission due to recurrence of the symptoms of HF. Therefore, every effort should be made to develop an optimal treatment strategy in this group of patients. It is worth mentioning a recently-started ToRsemide compArisioN With furoSemide FORManagement of Heart Failure (TRANSFORM-HF) 
study that aim is to compare the effects of furosemide versus torsemide on clinical outcomes over 12 months in approximately 6000 patients previously hospitalized for HF [26].

\section{Limitations of the study}

The main limitation of the study is the small sample size of the assessed population. The small number of participants did not enable assessment of the impact of torasemide and furosemide in different clinically relevant subgroups i.e. elderly, patients with chronic kidney disease, dilated cardiomyopathy. Noteworthy, the number of patients was sufficient to observe differences between the effects of torasemide and furosemide on clinical outcomes in HF patients. Moreover, the size of studied population made it possible to follow all subjects closely for the duration of the study and gathering considerably detailed information on each study participant.

\section{Conclusions}

Based on our study, patients randomized to torasemide had a higher likelihood of improvement of NYHA functional class, decreased fluid retention, elongated walking distance during $6 \mathrm{MWT}$ compared to patients randomized to furosemide entire follow-up period. This may indicate that diuretic effect of torsemide compared to furosemide can cause the higher loss of body water leading to greater weight loss that can facilitate walking. The above results and the impact of both drugs on the designed endpoint will confirm final results of TORNADO trial with the intention of being published by the end of 2020. However, further large-scale randomized trials comparing loop diuretic strategies would provide an opportunity to improve HF outcomes and reduce health care expenditures with currently available therapies.

\section{Conflict of interest: None declared}

\section{References}

1. Ponikowski P, Voors A, Anker S, et al. 2016 ESC Guidelines for the diagnosis and treatment of acute and chronic heart failure. Eur Heart J. 2016; 37(27): 2129-2200, doi: 10.1093/eurheartj/ ehw128.

2. Dyrla W, Kuch M. Torasemide and furosemide - similarities and differences. Medycyna Faktów. 2018; 11(4): 322-327, doi: 10.24292/01.mf.0418.11.

3. Palazzuoli A, Ruocco G, Ronco C, et al. Loop diuretics in acute heart failure: beyond the decongestive relief for the kidney. Crit
Care. 2015; 19: 296, doi: 10.1186/s13054-015-1017-3, indexed in Pubmed: 26335137.

4. Uchida T, Yamanaga K, Nishikawa M, et al. Anti-aldosteronergic effect of torasemide. Eur J Pharmacol. 1991; 205(2): 145-150, doi: 10.1016/0014-2999(91)90812-5, indexed in Pubmed: 1812004.

5. Goodfriend TL, Ball DL, Oelkers W, et al. Torsemide inhibits aldosterone secretion in vitro. Life Sci. 1998; 63(3): PL45-PL50, doi: 10.1016/s0024-3205(98)00265-3, indexed in Pubmed: 9698054.

6. Ballester MR, Roig E, Gich I, et al. Randomized, open-label, blinded-endpoint, crossover, single-dose study to compare the pharmacodynamics of torasemide-PR $10 \mathrm{mg}$, torasemide-IR $10 \mathrm{mg}$, and furosemide-IR $40 \mathrm{mg}$, in patients with chronic heart failure. Drug Des Devel Ther. 2015; 9: 4291-4302, doi: 10.2147/DDDT. S86300, indexed in Pubmed: 26273191.

7. DiNicolantonio JJ. Should torsemide be the loop diuretic of choice in systolic heart failure? Future Cardiol. 2012; 8(5): 707-728, doi: 10.2217/fca.12.54, indexed in Pubmed: 23013124.

8. López B, Querejeta R, González A, et al. Effects of loop diuretics on myocardial fibrosis and collagen type I turnover in chronic heart failure. J Am Coll Cardiol. 2004; 43(11): 2028-2035, doi: 10.1016/j.jacc.2003.12.052.

9. Mentz RJ, Buggey J, Fiuzat M, et al. Torsemide versus furosemide in heart failure patients: insights from Duke University Hospital. J Cardiovasc Pharmacol. 2015; 65(5): 438-443, doi: 10.1097/FJC.0000000000000212, indexed in Pubmed: 25945862.

10. Buggey J, Mentz RJ, Pitt B, et al. A reappraisal of loop diuretic choice in heart failure patients. Am Heart J. 2015; 169(3): 323-333, doi: 10.1016/j.ahj.2014.12.009, indexed in Pubmed: 25728721.

11. Mamcarz A, Filipiak KJJ, Drożdż J, et al. [Loop diuretics: old and new ones--which one to choose in clinical practice? Experts' Group Consensus endorsed by the Polish Cardiac Society Working Group on Cardiovascular Pharmacotherapy and Working Group on Heart Failure]. Kardiol Pol. 2015; 73(3): 225-232, doi: 10.5603/KP.2015.0051, indexed in Pubmed: 25791979.

12. Harada K, Izawa H, Nishizawa T, et al. Beneficial effects of torasemide on systolic wall stress and sympathetic nervous activity in asymptomatic or mildly symptomatic patients with heart failure: comparison with azosemide. J Cardiovasc Pharmacol. 2009; 53(6): 468-473, doi: 10.1097/FJC.0b013e3181a717f7, indexed in Pubmed: 19430310.

13. Balsam P, Ozierański K, Tymińska A, et al. The impact of torasemide on haemodynamic and neurohormonal stress, and cardiac remodelling in heart failure - TORNADO: a study protocol for a randomized controlled trial. Trials. 2017; 18(1): 36, doi: 10.1186/s13063-016-1760-z, indexed in Pubmed: 28114980.

14. Opolski G, Ozierański K, Lelonek M, et al. Adherence to the guidelines on the management of systolic heart failure in ambulatory care in Poland. Data from the international QUALIFY survey. Pol Arch Intern Med. 2017; 127(10): 657-665, doi: 10.20452/ pamw.4083, indexed in Pubmed: 28786405.

15. Stroupe KT, Forthofer MM, Brater DC, et al. Healthcare costs of patients with heart failure treated with torasemide or furosemide. Pharmacoeconomics. 2000; 17(5): 429-440, doi: 10.2165/00019053200017050-00002, indexed in Pubmed: 10977385.

16. Young M, Plosker GL. Torasemide: a pharmacoeconomic review of its use in chronic heart failure. Pharmacoeconomics. 2001; 19(6): 679-703, doi: 10.2165/00019053-200119060-00006, indexed in Pubmed: 11456215. 
17. Spannheimer A, Goertz A, Dreckmann-Behrendt B. Comparison of therapies with torasemide or furosemide in patients with congestive heart failure from a pharmacoeconomic viewpoint. Int J Clin Pract. 1998; 52(7): 467-471, indexed in Pubmed: 10622087.

18. Ozierański K, Balsam P, Kapłon-Cieślicka A, et al. Comparative analysis of long-term outcomes of torasemide and furosemide in heart failure patients in heart failure registries of the European Society of Cardiology. Cardiovasc Drugs Ther. 2019; 33(1): 77-86, doi: 10.1007/s10557-018-6843-5, indexed in Pubmed: 30649675.

19. Cosín J, Díez J. TORIC investigators. Torasemide in chronic heart failure: results of the TORIC study. Eur J Heart Fail. 2002; 4(4): 507-513, doi: 10.1016/s1388-9842(02)00122-8, indexed in Pubmed: 12167392.

20. Kido K, Shimizu M, Hashiguchi M. Comparing torsemide versus furosemide in patients with heart failure: A meta-analysis. J Am Pharm Assoc (2003). 2019; 59(3): 432-438, doi: 10.1016/j. japh.2019.01.014, indexed in Pubmed: 30846351.

21. Mentz RJ, Hasselblad V, DeVore AD, et al. Torsemide Versus Furosemide in Patients With Acute Heart Failure (from the ASCEND-HF Trial). Am J Cardiol. 2016; 117(3): 404-411, doi: 10.1016/j.amjcard.2015.10.059, indexed in Pubmed: 26704029.
22. Vargo DL, Kramer WG, Black PK, et al. Bioavailability, pharmacokinetics, and pharmacodynamics of torsemide and furosemide in patients with congestive heart failure. Clin Pharmacol Ther. 1995; 57(6): 601-609, doi: 10.1016/0009-9236(95)90222-8, indexed in Pubmed: 7781259.

23. Kasama S, Toyama T, Hatori T, et al. Effects of torasemide on cardiac sympathetic nerve activity and left ventricular remodelling in patients with congestive heart failure. Heart. 2006; 92(10): 1434-1440 , doi: 10.1136/hrt.2005.079764, indexed in Pubmed: 16621879.

24. Yamato M, Sasaki T, Honda K, et al. Effects of torasemide on left ventricular function and neurohumoral factors in patients with chronic heart failure. Circ J. 2003; 67(5): 384-390, doi: 10.1253/ circj.67.384, indexed in Pubmed: 12736474.

25. Broekhuysen J, Deger F, Douchamps J, et al. Torasemide, a new potent diuretic. Double-blind comparison with furosemide. Eur J Clin Pharmacol. 1986; 31 Suppl: 29-34, doi: 10.1007/ bf00541464, indexed in Pubmed: 3536530.

26. ToRsemide comparison With furosemide FORManagement of Heart Failure (TRANSFORM-HF) ClinicalTrials.gov Identifier: NCT03296813. 